\title{
Bronchoalveolar lavage fluid findings in children with hypersensitivity pneumonitis
}

\author{
F. Ratjen*, U. Costabel ${ }^{\#}$, M. Griese ${ }^{\Uparrow}$, K. Paul $^{+}$
}

Bronchoalveolar lavage fluid findings in children with hypersensitivity pneumonitis. F. Ratjen, U. Costabel, M. Griese, K. Paul. (C) ERS Journals Ltd 2003.

ABSTRACT: Bronchoalveolar lavage (BAL) has been shown to be useful in the diagnosis of hypersensitivity pneumonitis (HP) in adults, the typical constellation being lymphocytosis with a decrease in the CD4/CD8 ratio. Only limited data exist for the diagnostic value of BAL cytology in paediatric patients with this disorder.

Children aged 6-15 yrs $(n=9)$ with acute HP were studied. BAL was performed before initiation of anti-inflammatory treatment via a flexible bronchoscope in the middle lobe with $3 \mathrm{~mL} \cdot \mathrm{kg}$ body weight ${ }^{-1}$ normal saline warmed to body temperature; BAL cytology and lymphocyte surface markers were compared with age-matched controls.

The percentage of lymphocytes was significantly increased in all patients with HP. No significant differences were observed in the CD4/CD8 ratio between children without lung disease and those with HP. Increased expression of human leukocyte antigen-DR was found in seven of eight children with HP, whereas natural killer cells were elevated in five of eight children. Every patient had at least one of these two alterations in BAL fluid in addition to lymphocytosis.

It was concluded that while lymphocytosis is generally present in children with hypersensitivity pneumonitis, the CD4/CD8 ratio is not increased in these patients. Assessing natural killer cells and human leukocyte antigen-DR expression appears to be a helpful adjunct in the diagnosis of paediatric patients with this disorder.

Eur Respir J 2003; 21: 144-148.
*Dept of Paediatrics, University of Essen, \#Dept of Pneumonology and Allergy, Ruhrlandklinik, Essen, Dept of Paediatrics, Ludwig-MaximiliansUniversity, Munich, and ${ }^{+}$Dept of Pediatrics, Charité, Augustenburger Platz, Berlin, Germany.

Correspondence: F. Ratjen

Children's Hospital

University of Essen

Hufelandstr. 55

D-45122 Essen

Germany

Fax: 492017235983

E-mail: f.ratjen@uni-essen.de

Keywords: Children

bronchoalveolar lavage

hypersensitivity pneumonits

Received: May 12002

Accepted after revision: August 22002
Interstitial lung diseases represent a heterogeneous group of disorders that are relatively rare in children compared with adults [1,2]. Within this group of diseases, hypersensitivity pneumonitis (HP), also called allergic alveolitis, is distinct in that it can usually be related to an underlying cause, i.e. a precipitating antigen $[3,4]$. While individual cases of HP have been reported in the paediatric age group [5-10], little is known about the usefulness of different diagnostic techniques in children with this disorder.

The diagnosis of HP relies on a combination of a typical history, physical findings, pulmonary function tests, suggesting an interstitial lung disease, interstitial infiltrates on chest radiography and/or high-resolution computed tomography (CT), exposure to a possible allergen and serum precipitins against this antigen [11]. Whereas bioptic confirmation is rarely needed, bronchoalveolar lavage (BAL) has been shown to be a useful diagnostic tool to evaluate the local inflammatory process in adults with HP, since it appears to reflect the distribution of cell populations observed in biopsies [12]. The typical finding in BAL fluid in adult patients with HP, in the active phase of the disease, is lymphocytosis with a preponderance of CD8+ cells, resulting in a decreased CD4/CD8 ratio [13, 14]. Studies in children without lung disease have shown that this predominance of $\mathrm{CD} 8+$ cells is characteristic for children even in the absence of any disease process $[15,16]$.
To assess the diagnostic value of BAL in the paediatric age group, BAL fluid findings of children with HP were compared with BAL data from children without lung disease as an age-matched control group.

\section{Material and methods}

The study population consisted of nine children aged $6-15$ yrs (mean \pm SD: $10.1 \pm 3.1$ yrs) who presented at one of the university children's hospitals of Berlin, Essen or Munich during the years 1996-1999. The clinical data for the patient population are displayed in table 1. All patients presented with a history of fatigue, cough and decreased exercise tolerance lasting for 3-8 weeks. Dyspnoea was observed in four of nine patients at presentation. Chest radiograph showed diffuse reticular-nodular changes which were confirmed by high-resolution CT in all cases. Lung function and oxygen saturation at rest are displayed in table 1. An underlying allergen and serum precipitins against this antigen were found in all patients. All patients had an exercise test and showed decline of oxygen saturation below $90 \%$ during the test. Two patients received oxygen prior to bronchoscopy. All children were studied during the acute phase of the disease prior to initiation of anti-inflammatory treatment.

BAL was performed as part of the clinical diagnostic 
Table 1. - Subject characteristics

\begin{tabular}{|c|c|c|c|c|c|c|}
\hline Subject number & Sex & Antigen & Age yrs & FVC $\%$ pred & FEV1 $\%$ pred & $\begin{array}{c}{\mathrm{Sa}, \mathrm{O}_{2}}_{\text {in room }} \\
\text { air } \%\end{array}$ \\
\hline 1 & $\mathrm{~F}$ & Aspergillus & 6.0 & 62 & 66 & 95 \\
\hline 2 & M & Moulds & 7.0 & 57 & 61 & 98 \\
\hline 3 & $\mathrm{~F}$ & Parakeet & 8.8 & 59 & 35 & 94 \\
\hline 4 & $\mathrm{~F}$ & Parakeet & 9.8 & 62 & 61 & 91 \\
\hline 5 & $\mathrm{~F}$ & Moulds & 10.3 & 23 & 22 & 93 \\
\hline 6 & M & Parakeet & 11.8 & 25 & 26 & 93 \\
\hline 7 & M & Moulds & 13.0 & 40 & 49 & 92 \\
\hline 8 & $\mathrm{~F}$ & Pigeon & 14.8 & 35 & 40 & 89 \\
\hline 9 & M & Pigeon & 15.0 & 45 & 50 & 92 \\
\hline Mean \pm SD & & & $10.7 \pm 3.2$ & $45 \pm 16$ & $46 \pm 16$ & $93 \pm 3$ \\
\hline
\end{tabular}

FVC: forced vital capacity; FEV1: forced expiratory volume in one second; $\mathrm{Sa}_{\mathrm{a}} \mathrm{O}_{2}$ : arterial oxygen saturation; pred: predicted; M: male; F: female.

work-up via a flexible bronchoscope with an outer diameter of $3.5 \mathrm{~mm}$ in children $<10$ yrs of age and a $4.9 \mathrm{~mm}$ diameter in older children. Topical anaesthesia was achieved via inhalation with $2-4 \mathrm{~mL}$ of a $4 \%$ lidocaine solution prior to BAL and $1-4 \mathrm{~mL}$ of $2 \%$ lidocaine as needed while introducing the bronchoscope into the airways. Patients were sedated with midazolam $\left(0.2-0.3 \mathrm{mg} \cdot \mathrm{kg}\right.$ body weight $\left.{ }^{-1}\right)$ for the bronchoscopic procedure.

The bronchoscope was wedged in the middle lobe or one of its segments in all patients. BAL was performed as described earlier with $3 \mathrm{~mL} \cdot \mathrm{kg}$ body weight $^{-1}$ normal saline warmed to body temperature [17]. In children weighing $<20 \mathrm{~kg}, 3 \times 1 \mathrm{~mL} \cdot \mathrm{kg}^{-1}$ of normal saline was instilled and immediately withdrawn by gentle manual suction. In children weighing $>20 \mathrm{~kg}$, BAL was performed in aliquots of $20-\mathrm{mL}$ syringes up to a total volume of $3 \mathrm{~mL} \cdot \mathrm{kg}$ body weight $^{-1}$. The first aliquot of the recovered BAL fluid was treated separately; all other samples were pooled for analysis.

Bacterial cultures were obtained on $2 \mathrm{~mL}$ of the first BAL fluid sample prior to filtration. Subsequently, the first and pooled samples were filtered through one layer of sterile gauze to remove mucous. BAL fluid was centrifuged at $500 \times g$ for $10 \mathrm{~min}$. The cell suspension of the pooled BAL sample was washed three times in Eagle's minimal essential medium (MEM) containing $0.2 \%$ bovine serum albumin and $0.1 \%$ ethylene diamine tetra-acetic acid and resuspended in MEM. Bronchoalveolar cells were counted with a cell counter and cell viability was assessed by trypan exclusion. Differential cell counts were obtained from smears stained with May-Gruenwald-Giemsa. At least 600 cells were counted in each subject. BAL cytology was performed by personnel unaware of the diagnosis. In addition, all slides were reviewed by one of the authors. BAL cytology of both the pooled samples were compared with reference values obtained with the same BAL protocol in a population of 48 children aged $3-15$ yrs undergoing BAL for nonpulmonary illnesses [17].

Lymphocyte surface markers were assessed by the peroxidase anti-peroxidase method (PAP) for patients in Essen and by flow cytometry for patients in Berlin. The PAP technique has been described in detail elsewhere [18]. In summary, $10 \mu \mathrm{L}$ of the cell suspension is incubated on commercially available adhesive glass slides (Bio-Rad, Munich, Germany). Attached cells are fixed with a $0.05 \%$ solution of glutaraldehyde to block Fc receptors and preserve cell morphology. After washing with $0.3 \mathrm{M}$ glycine buffer to prevent binding of monoclonal antibodies to free aldehyde groups, a pre-incubation with a gelatin medium containing MEM with $0.2 \%$ gelantine Merck and $0.1 \%$ bovine serum albumin buffered with hygroethyl piperazine ethane sulphonic acid ( $\mathrm{pH} 7.4)$, was conducted for at least $15 \mathrm{~min}$ to reduce nonspecific binding of immunoglobulins to glass and cells. The slides were incubated with monoclonal antibodies to surface antigens for $15 \mathrm{~min}$. The following antibodies were used: OKT3 (CD3), OKT4 (CD4), and OKT8 (CD8) (Ortho Diagnositc Systems, Neckargemünd, Germany), B (CD20), IL2R1 (CD25) (Coulter Electronics, Krefeld, Germany) and Leu 7 (CD57) and Leu 19 (human leukocyte antigen (HLA)-DR) (Becton Dickinson, Heidelberg, Germany). The incubation with monoclonal antibodies was followed by rabbit antimouse immunoglobulin and swine antirabbit immunoglobulin for $10 \mathrm{~min}$ each. Rabbit PAP complex was added for 10 min. Peroxidase activity was assessed by staining with diaminobenzidinehydrogen peroxidase followed by postfixation with osmium tetraoxide $\left(\mathrm{OsO}_{4}\right)$. The slides were covered with glycine and a coverglass. Positively stained cells exhibit dark brown granular staining on the cell membrane visualised under a light microscope with a 400-1,000-fold magnification. At least 200 cells of each reaction were counted. Results of lymphocyte surface markers were compared with a reference population of children without lung disease that was described in detail previously [15].

Flow cytometry of lymphocyte subpopulations followed a two-colour protocol as described previously $[19,20]$. Lymphocyte subsets were determined for CD45, CD3, CD4, CD8, CD25 and HLA-DR (Becton Dickinson). Listmode data were further reviewed to exclude events which do not fulfil morphological (forward scatter versus sideward scatter) or immunological (CD3 expression) criteria for intact T-cells, and analysed for T-helper and suppressor cells 


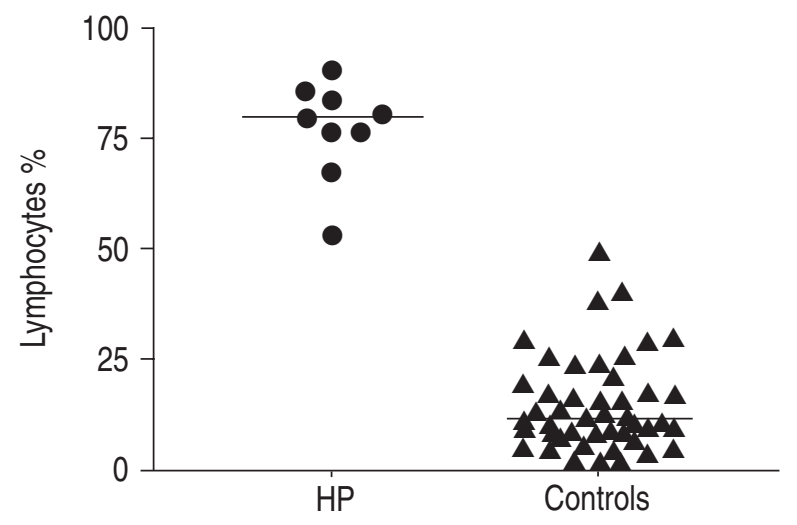

Fig. 1. - The percentage of lymphocytes in bronchoalveolar lavage (BAL) fluid of children with hypersensitivity pneumonitis (HP; 0 ) compared with children without pulmonary disease (controls; $\mathbf{\Lambda}$ ). Each point represents one individual. The solid line represents the median for each group. An increase in BAL lymphocytes was observed in all patients with HP.

(CD4, CD8), and T-cell activation markers (HLADR, CD25).

Cell counts were expressed as percentage of total cells and lymphocyte subsets as percentage of total lymphocytes. All parameters were tested for normal distribution with the Kolmogorov-Smirnov test. Parametric data were expressed as mean and $95 \%$ confidence interval (CI) (SD) and compared by t-test. The Wilcoxon test was used for nonparametric data. A value of $p<0.05$ was considered significant.

\section{Results}

BAL was well tolerated without any side-effects except for increased cough for the first $3 \mathrm{~h}$ following the procedure. Median total cell counts of patients with HP were $29 \times 10^{6}$ and therefore significantly increased compared with the reference population $(\mathrm{p}=0.0004)[17]$.

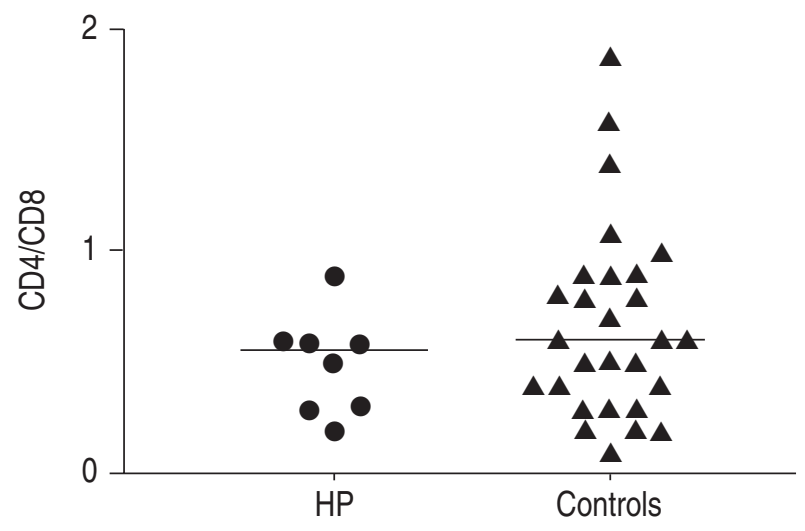

Fig. 2. $-\mathrm{CD} 4 / \mathrm{CD} 8$ ratio in bronchoalveolar lavage fluid of children with hypersensitivity pneumonitis (HP; - ) compared with children without pulmonary disease (controls; $\mathbf{\Delta}$ ). Each point represents one individual. The solid line represents the median for each group. There was no difference in the $\mathrm{CD} 4 / \mathrm{CD} 8$ ratio between the two groups.

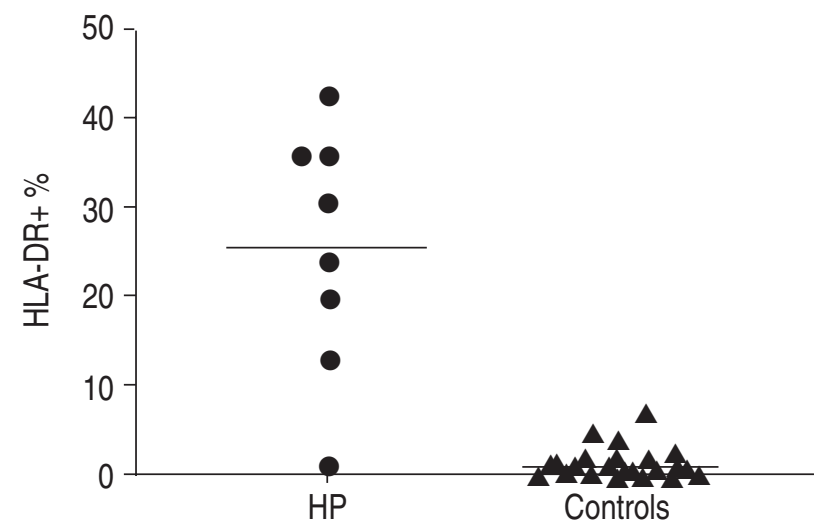

Fig. 3.- The percentage of lymphocytes expressing human leukocyte antigen (HLA)-DR in bronchoalveolar lavage fluid of children with hypersensitivity pneumonitis (HP; O) compared with children without pulmonary disease (controls; $\boldsymbol{\Delta}$ ). Each point represents one individual. The solid line represents the median for each group.

The percentage of lymphocytes in patients with HP was increased above the $95 \%$ CI of the reference population in all patients ( 80 versus $12.5 \%, \mathrm{p}<0.0001$; fig. 1). This increase in the percentage of lymphocytes was associated with a significant decrease in the percentage of macrophages ( 16 versus $84 \%, p<0.0001$ ). Foamy macrophages, which are absent in normal individuals, were observed in all patients; the percentages ranged $15-80 \%$ (median 30\%). Neutrophils showed only a moderate increase in patients with HP (median 3.3 versus $0.9 \%, \mathrm{p}=0.015$ ). Eosinophils were increased above the $95 \%$ CI of the reference population in five of nine patients with significant differences between the two groups (median 2.52 versus $0.4 \%, \mathrm{p}=0.001$ ). No differences between the two groups were observed for mast cells. Plasma cells were observed in five patients (range $0.1-0.3 \%$ ).

The CD4/CD8 ratio was similar in patients with HP and children without lung disease ( $\mathrm{p}=0.59$; fig. 2). An elevated percentage of lymphocytes expressing HLADR was seen in seven of eight patients with HP

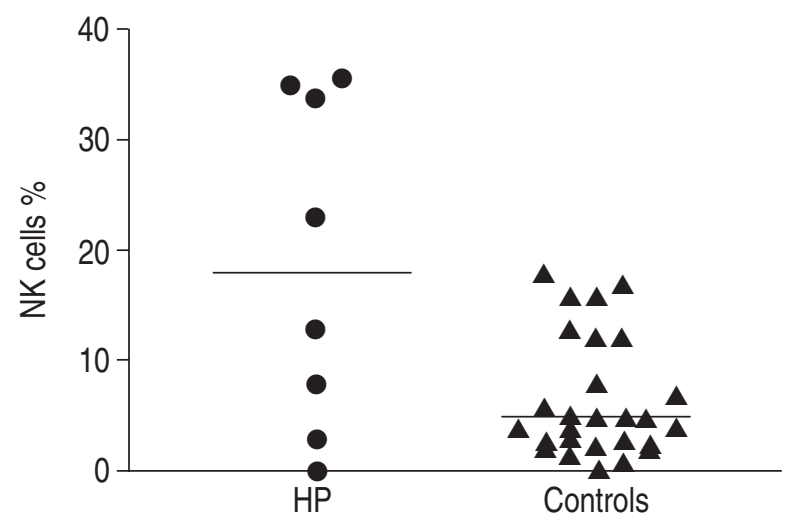

Fig. 4. - The percentage of natural killer (NK) cells (CD57) in bronchoalveolar lavage fluid of children with hypersensitivity pneumonitis (HP; $)$ compared with children without pulmonary disease (controls; $\boldsymbol{\Delta}$ ). Each point represents one individual. The solid line represents the median for each group. 
( $p<0.0001$; fig. 3). Although five of eight patients had natural killer (NK) cell counts above the $95 \%$ CI of the reference population, the comparison between groups failed to reach statistical significance $(\mathrm{p}=0.17$; fig. 4). All patients showed at least one of these alterations (increase in HLA-DR expression or increased NK cell numbers) in addition to BAL fluid lymphocytosis. Expression of the interleukin-2 receptor (CD25) was within the normal range in all patients (data not shown).

Allergen avoidance measures were implemented in all cases. In addition, patients received corticosteroid therapy that led to full recovery of lung function. All patients remained free of clinical symptoms and maintained normal values of lung function after cessation of corticosteroid therapy.

\section{Discussion}

This is the first study on differential cell counts and lymphocyte subpopulations of BAL fluid in paediatric patients with HP. The authors have shown that lymphocytosis is always present in patients during the acute phase of the disease. In contrast to studies in adults, the $\mathrm{CD} 4 / \mathrm{CD} 8$ ratio is within the normal range for paediatric patients. Assessing expression of HLADR appears to be of additional diagnostic value, as an increased expression was found in the majority of patients.

Individual cases of HP in children have been reported previously [5-10, 21, 22]. If BAL was performed in these cases, a predominance of CD8+ cells was observed. This was then thought to reflect typical findings similar to those observed in adults. However, BAL findings in these children were related to adult reference values. In previous studies of children without lung disease, the authors showed that the $\mathrm{CD} 4 / \mathrm{CD} 8$ ratio in normal children is lower than in healthy adults [15]. Therefore, the absence of a difference between the reference group and children with HP is most likely due to the fact that CD8+ cells are the predominant lymphocyte subtype in BAL fluid in this age group, even in the absence of any inflammatory stimulus.

Many cases of HP can be diagnosed without invasive diagnostic procedures [11,21]. A clinical history of exposure to an antigen is an important key to the diagnosis. Serum precipitins per se do not prove HP, but rather demonstrate exposure to an antigen source $[23,24]$. A high-resolution CT may be helpful and can show ground-glass opacities and/or centrilobular nodules [25, 26]. Lung biopsy is usually reserved for cases who fail to fulfil the clinical criteria for HP. BAL has the advantage of being less invasive and comparative studies in adults have shown a similar cellular pattern in BAL fluid and transbronchial biopsies [12]. BAL may therefore be useful in those patients who fail to fulfil the clinical criteria of HP, but in whom the entity is part of the differential diagnosis. BAL may also play a role in the follow-up of patients to assess the evolution of disease activity over time. Intuitively, this would seem to be especially helpful in children in whom corticosteroid therapy fails to normalise lung function, but this will need to be confirmed in future studies.

The alveolitis of HP can progress in several phases, according to the timing and duration of antigen exposure. A first phase of $448 \mathrm{~h}$, which is thought to be mediated by immune complexes is associated with an influx of neutrophils [3, 27]. It is followed by a cellular inflammatory reaction with lymphocytes mainly of the CD8 cell type as well as NK cells. In the chronic phase of the disease, CD8 lymphocytes are still found, but CD4 cells become more abundant [3]. Patients included in this study all had a recent onset of symptoms, present for $>1$ week, and can therefore be classified as reflecting the second phase of this inflammatory process. BAL was not used in the follow-up of these patients, because all patients recovered with full reconstitution of lung function to the normal range. This is not always the case in children with HP and the role of BAL in the follow-up of these children remains to be determined.

An increased expression of human leukocyte antigenDR and higher natural killer cell counts with normal levels of the interleukin-2 (CD25) receptor has also been observed in studies of adult patients with hypersensitivity pneumonitis [3]. The relevance of this finding in discriminating hypersensitivity pneumonitis from other interstitial lung diseases in children remains unclear at the present time. Increased human leukocyte antigen-DR expression is found in adult patients with bronchiolitis obliterans with organising pneumonia, while it is usually absent in idiopathic pulmonary fibrosis [28]. The latter entities are very rare in children and controversy exists over whether idiopathic pulmonary fibrosis occurs at all in children. Therefore, more information on the spectrum of interstitial lung diseases in children is needed to clarify the role of bronchoalveolar lavage in the differential diagnosis of paediatric patients with interstitial lung diseases.

\section{References}

1. Bokulic RE, Hilman BC. Interstitial lung disease in children. Pediatr Clin North Am 1994; 41: 543-567.

2. Fan LL, Kozinetz CA, Deterding RR, Brugman SM. Evaluation of a diagnostic approach to pediatric interstitial lung disease. Pediatrics 1998; 101: 82-85.

3. Costabel U. The alveolitis of hypersensitivity pneumonitis. Eur Respir J 1988; 1: 5-9.

4. Ando M, Suga M. Hypersensitivity pneumonitis. Curr Opin Pulm Med 1997; 3: 391-395.

5. Stiehm ER, Reed CE, Tooley WH. Pigeon breeder's lung in children. Pediatrics 1967; 39: 904-915.

6. Heersma JR, Emanuel DA, Wenzel FJ, Gray RL. Farmer's lung in a 10-year-old girl. J Pediatr 1969; 75 : 704-706.

7. Bureau MA, Fecteau C, Patriquin M, Rola-Pleszczynski M, Masse S, Begin R. Farmer's lung in early childhood. Am Rev Respir Dis 1979; 119: 671-675.

8. Keith HH, Holsclaw DS Jr, Dunsky EH. Pigeon breeder's disease in children: a family study. Chest 1981; 79: 107-110.

9. Thorshauge H, Fallesen I, Ostergaard PA. Farmer's lung in infants and small children. Allergy 1989; 44: $152-155$. 
10. McClellan JS, Albers GM, Noyes BE, Sotelo C, Petterchak JA, Knutsen AP. B-lymphocyte aggregates in alveoli from a child with hypersensitivity pneumonitis. Ann Allergy Asthma Immunol 1999; 83: 357-360.

11. Richerson HB, Bernstein IL, Fink JN, et al. Guidelines for the clinical evaluation of hypersensitivity pneumonitis. J Allergy Clin Immunol 1989; 84: 839844.

12. Semenzato G, Chilosi M, Ossi E, et al. Bronchoalveolar lavage and lung histology. Comparative analysis of inflammatory and immunocompetent cells in patients with sarcoidosis and hypersensitivity pneumonitis. $\mathrm{Am}$ Rev Respir Dis 1985; 132: 400-404.

13. Costabel U, Bross KJ, Marxen J, Matthys $\mathrm{H}$. T-lymphocytosis in bronchoalveolar lavage fluid of hypersensitivity pneumonitis. Changes in profile of T-cell subsets during the course of the disease. Chest 1984; 85: 514-522.

14. Costabel U, Bross KJ, Ruhle KH, Löhr GW, Matthys $\mathrm{H}$. Ia-like antigens on T-cells and their subpopulations in pulmonary sarcoidosis and in hypersensitivity pneumonitis. Analysis of bronchoalveolar lavage and blood lymphocytes. Am Rev Respir Dis 1985; 131: 337-342.

15. Ratjen F, Bredendiek $\mathrm{M}$, Zheng $\mathrm{L}$, Brendel $\mathrm{M}$, Costabel U. Lymphocyte subsets in bronchoalveolar lavage fluid of children without bronchopulmonary disease. Am J Respir Crit Care Med 1995; 152: 174 178.

16. Riedler J, Grigg J, Stone C, Tauro G, Robertson CF. Bronchoalveolar lavage cellularity in healthy children. Am J Respir Crit Care Med 1995; 152: 163-168.

17. Ratjen F, Bredendiek M, Brendel M, Meltzer S, Costabel U. Differential cytology of bronchoalveolar lavage fluid in normal children. Eur Respir J 1994; 7 : $1865-1870$.

18. Costabel U, Bross KJ, Matthys H. The immunoperoxidase slide assay. A new method for the demonstration of surface antigens on bronchoalveolar lavage cells. Bull Eur Physiopathol Respir 1985; 21: 381-387.

19. Hoser G, Kawiak J, Domagala-Kulawik J, Kopinski P, Droszcz W. Flow cytometric evaluation of lymphocyte subpopulations in BALF of healthy smokers and nonsmokers. Folia Histochem Cytobiol 1999; 37: 25-30.

20. Loppow D, Böttcher M, Gercken G, Magnussen H, Jörres RA. Flow cytometric analysis of the effect of dithiothreitol on leukocyte surface markers. Eur Respir J 2000; 16: 324-329.

21. Grech V, Vella C, Lenicker H. Pigeon breeder's lung in childhood: varied clinical picture at presentation. Pediatr Pulmonol 2000; 30: 145-148.

22. Du Marchie Sarvas GJ, Merkus PJ, de Jongste JC. A family with extrinsic allergic alveolitis caused by wild city pigeons: a case report. Pediatrics 2000; 105: E62.

23. Burrell R, Rylander R. A critical review of the role of precipitins in hypersensitivity pneumonitis. Eur J Respir Dis 1981; 62: 332-336.

24. Reynaud C, Slosman DO, Polla BS. Precipitins in bird breeder's disease: how useful are they? Eur Respir $J$ 1990; 3: 155-161.

25. Lynch DA, Hay T, Newell JD Jr, Divgi VD, Fan LL. Pediatric diffuse lung disease: diagnosis and classification using high-resolution CT. Am J Roentgenol 1999; 173: 713-718.

26. Lynch DA, Rose CS, Way D, King TE. Hypersensitivity pneumonitis: sensitivity of high-resolution CT in a population based study. Am J Roentgenol 1992; 159: 469-472.

27. Fournier E, Tonnel AB, Gosset P, Wallaert B, Ameisen JC, Voisin C. Early neutrophil alveolitis after antigen inhalation in hypersensitivity pneumonitis. Chest 1985; 88: 563-566.

28. Costabel U, Teschler H, Guzman J. Bronchiolitis obliterans organizing pneumonia (BOOP): the cytological and immunocytological profile of bronchoalveolar lavage. Eur Respir J 1992; 5: 791-797. 